\title{
openheart Sudden cardiac death in adults with congenitally corrected transposition of the great arteries
}

\author{
A McCombe, ${ }^{1,2} \mathrm{~F}$ Touma, ${ }^{1,2}$ D Jackson, ${ }^{1}$ C Canniffe, ${ }^{1,3} \mathrm{P}$ Choudhary, ${ }^{1,2,4}$ \\ L Pressley, ${ }^{1,2}$ D Tanous, ${ }^{1,2,4}$ Peter J Robinson, ${ }^{1,2}$ D Celermajer ${ }^{1,2}$
}

To cite: McCombe A, Touma F, Jackson D, et al. Sudden cardiac death in adults with congenitally corrected transposition of the great arteries. Open Heart 2016;3:e000407. doi:10.1136/openhrt-2016000407

Received 11 January 2016 Revised 30 April 2016 Accepted 24 May 2016

\section{(D) CrossMark}

${ }^{1}$ Department of Cardiology, Royal Prince Alfred Hospital, Sydney, New South Wales, Australia

${ }^{2}$ Discipline of Medicine, Central Clinical School, University of Sydney, Sydney, New South Wales, Australia ${ }^{3}$ Department of Cardiology, Mater Misericordiae Hospital, Dublin, Ireland

${ }^{4}$ Department of Cardiology, Westmead Hospital, Sydney, New South Wales, Australia

Correspondence to Professor David Celermajer; david.celermajer@email.cs. nsw.gov.au

\section{ABSTRACT}

Background: Congenitally corrected transposition of the great arteries (CCTGA) is a rare congenital heart disease. There have been only few reports of sudden cardiac death (SCD) in patients with CCTGA and reasonable ventricular function.

Methods: A retrospective review of the medical records of all patients attending our adult congenital heart centre, with known ccTGA.

Results: From a database of over 3500 adult patients with congenital heart disease, we identified $39(\sim 1 \%)$ with ccTGA and 'two-ventricle' circulations. $65 \%$ were male. The mean age at diagnosis was $12.4 \pm 11.4$ years and the mean age at last time of review was $34.3 \pm 11.3$ years. 24 patients $(56 \%)$ had a history of surgical intervention. $8(19 \%)$ had had pacemaker implantation and 2 had had a defibrillator implanted for non-sustained ventricular tachycardia (NSVT). In 544 years of patient follow-up, there had been five cases of SCD in our population; 1 death per 109 patient-years. Two of these patients had had previously documented supraventricular or NSVT. However, they were all classified as New York Heart Association (NYHA) class I or II, and systemic (right) ventricular function had been recorded as normal, mildly or mildly-moderately impaired, at most recent follow-up. Conclusions: Our experience suggests the need for improved risk stratification and/or surveillance for malignant arrhythmia in adults with ccTGA, even in those with reasonable functional class on ventricular function.

\section{INTRODUCTION}

Congenitally corrected transposition of the great arteries (ccTGA) is a rare form of congenital heart disease characterised by atrioventricular $(\mathrm{AV})$ and ventriculoarterial discordance. It is termed 'congenitally corrected' because deoxygenated systemic venous blood flows into the pulmonary circulation and oxygenated pulmonary venous blood returns to the systemic circulation in the correct physiological manner, albeit via the 'incorrect' ventricle. ${ }^{1}$

\section{KEY QUESTIONS}

What is already known about this subject?

- Congenitally corrected transposition of the great arteries (CCTGA) is a rare but important congenital cardiac lesion, as it is frequently associated with other lesions and premature morbidity and even mortality. As it is rare, however, long-term outcome data in adults with ccTGA concerning the impact of arrhythmias, valve and ventricular failure are poorly documented, as is risk stratification for sudden death.

What does this study add?

- In our relatively large single-centre experience of 39 adults with ccTGA, sudden cardiac death in otherwise well patients was observed at an unexpectedly high rate of 1 death per 109 patientyears. $5 \%$ of our patients required defibrillator implantation for non-sustained ventricular tachycardia and pacemaker implantation was required in $19 \%$. Our study demonstrates the frequent occurrence of serious electrical complications, even in patients with good functional class and relatively preserved systemic ventricular function.

How might this impact on clinical practice?

- Our experience suggests the need for improved risk stratification and/or surveillance for malignant arrhythmia and conduction system disease in all adults with ccTGA.

ccTGA comprises $<1 \%$ of all reported congenital heart lesions. ${ }^{2-4}$ The population incidence has been reported to range from 0.02 to 0.07 per 1000 live births. It frequently occurs with one or more associated cardiac lesions, ${ }^{5}$ with an abnormal or Ebstein's-like tricuspid valve being reported in up to $91 \%$ of cases, in some series. ${ }^{6}$

Reports on the long-term outcomes of adults with ccTGA have noted an increasing frequency of supraventricular and ventricular arrhythmias, conduction abnormalities, systemic AV valvular regurgitation and systemic (right) ventricular failure with increasing 
age. ${ }^{5}$ However, wide variations in the reported onset and frequency of complications mean the implications of such sequelae on morbidity and mortality remain unclear.

Prompted by several cases of unexpected sudden cardiac death (SCD) in our patients with ccTGA, we reviewed our experience in this regard.

\section{METHODS}

The study was approved by our Institutional Ethics Committee.

Patients with a diagnosis of ccTGA were identified from an existing database at our tertiary referral centre for adult congenital heart disease (ACHD). All those $\geq 16$ years of age, who had been reviewed at least once since 1995 with a diagnosis of ccTGA, regardless of associated heart defects, were included, except if they had 'single ventricle'-type circulations $(n=4)$. Medical records were reviewed between 2012 and 2014, including clinic reviews, results of investigations, catheterisation or electrophysiology reports and any surgical/transcatheter intervention records. Test results and patient symptoms reported are those that were documented at the most recent follow-up. Transthoracic echocardiography was used for the assessment of ventricular function. During the study period, patients with ccTGA did not undergo routine serial cardiac MRI due to limited availability of the modality. Transthoracic echocardiography was performed by experienced sonographers in ACHD. As markers for right ventricular (RV) function are not defined for the systemic right ventricle, qualitative assessment of RV function was performed and compared to previous studies.

The Australian National Death Index, a nationwide registry of deaths, was consulted to confirm vital status for all patients, with the ascertainment date being the end of 2013.

SCD was defined as death within 1 hour of onset of symptoms, which occurred in the patient's usual state of health or if it was unwitnessed during sleep, consistent with previous studies. ${ }^{78}$

\section{Statistical methods}

Analysis was performed using SPSS V.20 (IBM, Armonk, New York, USA). Data for categorical variables are reported as frequency and percentage $(\%)$, and data for continuous variables are summarised using mean \pm SD.

\section{RESULTS}

\section{Baseline patient characteristics}

A total of 39 patients with ccTGA were identified; 26 $(67 \%)$ were male. The mean age at diagnosis was 12.4 \pm 11 .4 years. The mean age at presentation to our ACHD centre was $26.4 \pm 10.4$ years.

Nine had isolated ccTGA with levocardia and one patient had isolated ccTGA with dextrocardia. The remaining 29 patients had between one and seven

\begin{tabular}{lcc} 
Table 1 Associated congenital cardiac & abnormalities \\
\hline Congenital cardiac lesion & $\mathbf{n}$ & Per cent \\
\hline Pulmonary or subpulmonary stenosis & 13 & 33 \\
VSD & 18 & 46 \\
Ebstein's anomaly of the TV & 6 & 15 \\
ASD & 6 & 15 \\
Dextrocardia & 5 & 13 \\
PDA & 2 & 5
\end{tabular}

ASD, atrial septal defect; PDA, patent ductus arteriosus; TV, tricuspid (systemic atrioventricular) valve; VSD, ventricular septal defect.

associated congenital heart abnormalities. Associated congenital abnormalities are outlined in table 1 .

The mean age at last review was $34.3 \pm 11.3$ years. A total of $24(62 \%)$ patients had been reviewed in the last 2 years. The remaining 15 patients were last seen by a cardiologist within a median period of 6.34 years (IQR $2.7-14.5$ years).

In 544 years of patient follow-up, there have been five cases of SCD in our ccTGA population; 1 death per 109 patient-years. The mean age at time of death was 34 years.

\section{Prior surgeries}

A total of $62 \%$ of patients $(n=24)$ had had at least one cardiothoracic surgical procedure. The most common procedures were ventricular septal defect (VSD) closure, atrial septal defect (ASD) closure, left ventricle to pulmonary artery (LV-PA) conduit placement and systemic AV valve replacement. A total of $44 \%(n=8)$ of patients with a VSD and all of the patients with an ASD had their respective lesions surgically repaired. LV-PA conduits were required in six patients for pulmonary stenosis or atresia. Tricuspid valves were replaced with mechanical prostheses in six patients, with two patients requiring a re-replacement of the implanted valve and one requiring excision of obstructive tissue around the prosthesis.

\section{Systemic ventricular dysfunction and tricuspid valve function}

All patients had at least one echocardiogram. A total of 39 patients had had qualitative transthoracic echocardiographic (TTE) assessment of systemic ventricular function. At their most recent assessment, systemic ventricular function was described as good or reasonable $(\mathrm{n}=10)$, mildly impaired $(\mathrm{n}=13)$, mildly-moderately impaired $(n=11)$, moderately impaired $(n=1)$, moderately-severely impaired $(n=1)$ or severely impaired $(n=3)$.

A total of $56 \%(\mathrm{n}=22)$ of patients were documented as having 'significant' tricuspid regurgitation (TR) at the time of last follow-up. Significant TR was defined qualitatively as more than moderate regurgitation on TTE.

\section{Arrhythmias}

A total of $91 \%$ of patients had a documented conduction abnormality. Prevalence of specific arrhythmias is outlined in table 2. 
Table 2 Documented arrhythmias in patients with ccTGA

\begin{tabular}{lcc}
\hline Arrhythmia & $\begin{array}{l}\text { Frequency } \\
\text { (n) }\end{array}$ & $\begin{array}{c}\text { Per } \\
\text { cent }\end{array}$ \\
\hline Heart block & 14 & 36 \\
Third-degree heart block & 9 & 23 \\
Second-degree heart block & 0 & 0 \\
First-degree heart block & 5 & 13 \\
Supraventricular tachycardia & 6 & 15 \\
$\quad$ Atrial fibrillation & 6 & 15 \\
Atrial flutter & 4 & 10 \\
Ventricular tachycardia & & \\
$\quad$ Non-sustained ventricular & 4 & - \\
tachycardia & & \\
$\quad$ Sustained ventricular & - & - \\
tachycardia & & \\
$\quad$ Ventricular tachycardia & - & \\
Ventricular fibrillation & - & \\
\hline ccTGA, congenitally corrected transposition of the great arteries.
\end{tabular}

Heart block was present in 14 patients (36\%). Eight patients with complete heart block had permanent pacemakers (PPM) implanted at an average age of 20 years (range 8.5 months -45 years).

Atrial fibrillation was present in six patients, with two having had a slow ventricular rate, necessitating PPM insertion. Atrial flutter was present in four patients, three of whom had a documented history of atrial flutter and fibrillation.

Four patients had documented non-sustained ventricular tachycardia (NSVT). An implantable cardioverter defibrillator (ICD) was inserted in a man aged 33 years with NSVT who had a PPM implanted for complete heart block 4 years prior. A second patient, a woman aged 32 years, had an ICD inserted for NSVT and atrial flutter. At most recent follow-up, both patients with ICDs were New York Heart Association (NYHA) class I and had no documentation of antitachycardia pacing therapy on device interrogation.

\section{Symptoms and functional status}

Thirty-five patients had an NYHA class documented in their medical records at most recent follow-up. Of these, 21 were NHYA I and 14 were NHYA II. No patient was documented as having an NHYA functional class $>$ II. Other symptoms recorded at the time of last follow-up included palpitations (53.5\%), dyspnoea $(53.5 \%)$ and fatigue $(39.5 \%)$. A total of $26 \%$ of the patients had a documented history of heart failure. Of the deceased patients, only one patient was on antifailure therapy with diuretics and digoxin. Diuretics were prescribed for 12 patients and digoxin was prescribed for 9 patients in total. A total of 2 of the deceased patients and 11 of the surviving patients had been prescribed long-term warfarin therapy. Case 2 had a prosthetic valve and case 3 was on warfarin for paroxysmal atrial fibrillation.

There was no correlation between reported patient symptoms and the degree of recorded RV dysfunction.

\section{CASES OF SCD}

Four patients ( 1 female, 3 males) in this cohort of 39 patients with ccTGA died suddenly and an additional male (case 2) had suspected SCD. Four of these patients had been seen in the ACHD centre in the year preceding their death.

\section{Case 1}

A woman aged 34 years with ccTGA, a small VSD and mild Ebstein's anomaly had had her ccTGA diagnosed on TTE at age 27. She had had no surgical interventions and was a current smoker with no regular alcohol intake. She was reviewed at the ACHD service 4 months prior to her death for increasing dyspnoea on moderate exertion and an isolated episode of ankle oedema. Her chest radiograph showed mild cardiomegaly. TTE revealed mild aortic regurgitation, mild-moderate TR and a mildly dilated systemic ventricle with good contractility.

ECG showed infrequent monomorphic premature ventricular complexes, first-degree AV block with PR interval of $251 \mathrm{~ms}$ and QRS duration of $96 \mathrm{~ms}$. She was not on any medication. Twenty-four-hour Holter monitor revealed sinus rhythm for the majority over the monitoring period with a mean heart rate of 76 beats per minute (bpm), first-degree AV block but no higher grade AV block. There were frequent ventricular extrasystoles with two runs of NSVT of six and nine beats, respectively. The events were not associated with symptoms.

The patient died suddenly in her sleep 9 weeks later. A posthumous discussion with a family member revealed that she had had palpitations and dizziness over the preceding 4 weeks. She had not presented for medical review for these symptoms.

\section{Case 2}

A man aged 29 years with ccTGA and an associated infracristal VSD and systemic AV valve incompetence (mild-moderate) was diagnosed on angiography at 11 months of age. He underwent VSD repair and systemic AV valve replacement (Carbomedics $25 \mathrm{~mm}$ prosthesis) at 7 years of age. A year later, the prosthetic valve had thrombosed despite warfarin anticoagulation and was subsequently replaced with a $23 \mathrm{~mm}$ St Jude prosthesis. Other medications included digoxin and diuretics. He was a lifelong non-smoker and did not consume excessive amounts of alcohol.

In the months prior to his death, the patient had recurrent episodes of severe left-sided chest discomfort and nausea for 2-3 months, appearing to coincide with periods of subtherapeutic anticoagulation (international normalised ratio (INR) 1.2-1.4). He was reviewed by a cardiologist 4 months prior to his death. Examination was unremarkable and there were no signs of heart failure. His ECG revealed sinus bradycardia with occasional premature ventricular complexes, PR duration $202 \mathrm{~ms}$ and QRS duration $106 \mathrm{~ms}$. Twenty-four-hour 
Holter monitoring revealed an average rate of $58 \mathrm{bpm}$, occasional atrial and ventricular ectopy with rare ventricular couplets. There were no sinus pauses. Chest radiograph demonstrated a globular heart that was unchanged from previous chest radiographs. TTE showed mild obstruction of the valve prosthesis (with good movement of both disc leaflets) and mild impairment of the systemic ventricle.

Owing to the risk of prosthetic valve thrombosis due to subtherapeutic INR, he was bridged with subcutaneous enoxaparin when INR was subtherapeutic and a target INR of 2.5-4 was established. At clinical evaluation 2 months before his death, the chest pain had settled, and he was otherwise well.

The National Death Index registry identified the cause of death as a motor vehicle accident due to the patient's car colliding with a stationary object, resulting in multiple injuries and death. Arrhythmia may have been a significant contributory factor; however, this cannot definitively be determined.

\section{Case 3}

A man aged 31 years diagnosed with ccTGA at 21 years of age when investigated for an incidental murmur. He had associated mild Ebstein's malformation of the tricuspid valve.

He developed recurrent atrial arrhythmias, which were pharmacologically controlled. His most recent medications included sotalol, digoxin, trandolapril, frusemide and paroxetine.

Significant family history included a sister who had a double outlet right ventricle. He also had a history of substance abuse with alcohol, cigarette and marijuana smoking. The most recent medical correspondence, however, suggests he had been abstinent from these for the previous 2 years.

The patient was reviewed by the ACHD service 1 month prior to his death. ECG confirmed he had sinus rhythm with ventricular bigeminy, with no QT prolongation. TTE revealed a moderately dilated and hypertrophied systemic ventricle with mild-moderate systolic dysfunction. Mild apical displacement of the tricuspid valve with mild regurgitation was noted. Left atrium was mildly dilated. He had normal left ventricular contractility with no outflow tract obstruction.

The patient had a witnessed collapse at home while making breakfast. Emergency services were called and cardiopulmonary resuscitation was performed. He was pronounced dead at a local district hospital on arrival.

\section{Case 4}

A man aged 34 years with ccTGA, dextrocardia and prior surgical repair of an ASD in childhood was referred to the clinic at the age of 25 years. He was symptomatic with multiple episodes of presyncope. ECG revealed sinus arrhythmia. Echocardiography revealed moderate regurgitation of the systemic AV valve, but the systemic RV function was only mildly impaired. Holter monitoring did not show any significant abnormalities apart from intermittent sinus bradycardia, and an exercise stress test showed only mildly reduced exercise capacity with no chronotropic incompetence. Although scheduled for an electrophysiology study to assess for ventricular arrhythmia, there was no documentation to suggest that this had been performed. He had an SCD with a 4-year period of loss to further follow-up, prior to his death.

\section{Case 5}

A man aged 27 years with ccTGA with right atrial isomerism, a pulmonary conduit and a small ASD was referred for management of his impaired subpulmonary left ventricle. The systemic ventricle had only mildly impaired systolic function with mild regurgitation of the systemic $\mathrm{AV}$ valve. In contrast, the subpulmonic left ventricular function was moderately impaired, with moderatesevere right $\mathrm{AV}$ valvular regurgitation, and a gradient of $40 \mathrm{~mm} \mathrm{Hg}$ was noted between the left ventricle and right atrium. The patient died suddenly at home in the year following review, of uncertain cause. Clinical characteristics of these patients are summarised in table 3 .

\section{Other deaths}

There was one non-SCD in our cohort, in a woman aged 64 years with ccTGA. She underwent cardiac transplantation at age 57 years and died due to graft rejection.

\section{DISCUSSION \\ Our findings}

Over a period of 15 years, 5 of 39 patients with ccTGA died suddenly (12.8\%), giving an HR of 1 per 109 patient-years of follow-up. SCD was strongly suspected in one patient; however, this was not confirmed. The suspected cause of death in the other four cases was malignant arrhythmia.

\section{Causes of death in CcTGA}

It has been estimated that the lifetime incidence of SCD in the ACHD (of any diagnosis) population is $19-26 \% .^{9-11}$ Koyak et al identified a number of clinical parameters found to be associated with SCD in adults with a broad spectrum of congenital heart disease, including systemic right ventricles. ${ }^{7}$ These included supraventricular tachycardia, moderate-severe systemic ventricular dysfunction, moderate-severe subpulmonary ventricular dysfunction, increased QRS duration and QT dispersion.

Little has been published in the medical literature about the specific causes of death in patients with ccTGA. These patients are increasingly subject to tricuspid valvular regurgitation and consequently systemic ventricular dysfunction and heart failure. ${ }^{58}$

In patients with dextro TGA (D-TGA) and a history of Senning or Mustard repair, the lifetime incidence of SCD is estimated to be between $2 \%$ and $15 \%$. Connelly et al reported an incidence of SCD of $8 \%$ in 52 adult 
Table 3 Summary of case reports of sudden cardiac death in patients with ccTGA

\begin{tabular}{|c|c|c|c|c|c|}
\hline & Case 1 & Case 2 & Case 3 & Case 4 & Case 5 \\
\hline Age (years) & 34 & 29 & 31 & 34 & 30 \\
\hline $\begin{array}{l}\text { Associated congenital } \\
\text { heart lesions }\end{array}$ & $\begin{array}{l}\text { Ebstein's } \\
\text { anomaly } \\
\text { VSD }\end{array}$ & VSD & $\begin{array}{l}\text { Ebstein's } \\
\text { anomaly }\end{array}$ & ASD & $\begin{array}{l}\text { ASD } \\
\text { PS }\end{array}$ \\
\hline $\begin{array}{l}\text { Previous surgical } \\
\text { intervention }\end{array}$ & $\begin{array}{l}\text { No previous } \\
\text { surgery }\end{array}$ & $\begin{array}{l}\text { VSD repair } \\
\text { Tricuspid valve } \\
\text { replacement } \\
(1988,1989)\end{array}$ & $\begin{array}{l}\text { No previous } \\
\text { surgery }\end{array}$ & ASD repair & Pulmonary conduit \\
\hline $\begin{array}{l}\text { RV function } \\
\text { (at last follow-up) }\end{array}$ & Normal & Mildly impaired & $\begin{array}{l}\text { Mildly-moderately } \\
\text { impaired }\end{array}$ & $\begin{array}{l}\text { Mildly } \\
\text { impaired }\end{array}$ & Mildly impaired \\
\hline Tricuspid regurgitation & Mild-moderate & Mild-moderate & Mild & $\begin{array}{l}\text { Mild- } \\
\text { moderate }\end{array}$ & Mild \\
\hline $\begin{array}{l}\text { Arrhythmia } \\
\text { documentation }\end{array}$ & $\begin{array}{l}\text { First-degree AV } \\
\text { block } \\
\text { NSVT }\end{array}$ & $\begin{array}{l}\text { Occasional atrial and } \\
\text { ventricular ectopics }\end{array}$ & $\begin{array}{l}\text { Atrial arrhythmia } \\
\text { Ventricular } \\
\text { bigeminy }\end{array}$ & $\begin{array}{l}\text { Sinus } \\
\text { bradycardia } \\
(41 / \mathrm{min})\end{array}$ & $\begin{array}{l}\text { No arrhythmias } \\
\text { documented }\end{array}$ \\
\hline Symptoms & $\begin{array}{l}\text { Palpitations } \\
\text { Presyncope }\end{array}$ & Chest pain & No symptoms & Presyncope & No symptoms \\
\hline
\end{tabular}

patients with ccTGA in 1996, an incidence similar to our findings. However, they had a much higher incidence of death from any cause in their group, with $25 \%$ of their adult patients with ccTGA dead at a mean age of 38.5 \pm 12.5 years. They reported that the commonest cause of death in their cohort was progressive failure of the systemic ventricle $(50 \%) .{ }^{12}$ Despite a similar age profile of our cohort, we have not documented any deaths due to progressive RV dysfunction. Except for one patient who died due to graft rejection, most of the deaths in our group were as a result of SCD, in patients with reasonable RV function, perhaps reflecting an increasing prevalence of arrhythmogenic deaths in patients with ccTGA in the modern era.

\section{Risk stratification}

Although we were not able to identify any clinical predictors of SCD in our patients, our study does highlight the need for improved algorithms for risk stratification of patients with ccTGA. Prieto et al found that TR was the only independent predictor of death in their cohort of 40 patients with ccTGA. They reported a 20-year unoperated survival of $100 \%$ in those with less than moderately severe TR, compared with $60 \%$ in those with moderately severe-severe TR. ${ }^{13}$ Connelly et $a l^{12}$ reported that systemic RV failure was the cause of death in over $50 \%$ of their cohort. Our patients who experienced SCD did not have significantly impaired RV function or significant TR, so these parameters did not identify these patients as 'high risk' or predict their adverse outcomes.

Patients with TGA and a Senning or Mustard repair also rely on their right ventricle to support their systemic circulation. Although patients with atrial switch repair have other associated complications and are not an identical comparison cohort to patients with ccTGA, the presence of a systemic right ventricle is associated with heart failure. Piran et $a l^{14}$ report a high prevalence of heart failure and associated mortality in patients with systemic right ventricles. Within this cohort, the prevalence was higher in patients with ccTGA compared with those with an atrial switch repair. Kammeraad et $a l^{15}$ looked at such a population of patients and found that symptoms of arrhythmia or heart failure, or a documented history of arrhythmia (atrial fibrillation or flutter) at most recent follow-up, increased SCD risk. A recent study including patients with ccTGA $(n=25)$ and TGA with a Senning or Mustard repair $(n=63)$ found that MRI assessment of RV end-diastolic volume index (RVEDVI) and peak systolic blood pressure (SBP) on exercise testing were the best predictors of adverse clinical events (including death, worsening heart failure and arrhythmias). Symptoms (NYHA functional class >II) and absence of sinus rhythm were also found to be determinants of clinical events. They reported that these predictors were similar in those with ccTGA and those with TGA and a history of Senning or Mustard repair. ${ }^{16}$

\section{Possible prevention of SCD: ventricular rhythm abnormalities and ICD implantation}

Tachyarrhythmia risk, defibrillator implant risks, longterm outcomes and rates of appropriate and inappropriate ICD therapies are not well characterised in patients with ccTGA. There have been few incidents of malignant ventricular arrhythmia in patients with ccTGA that have been documented in the literature. Four publications have identified patients with ccTGA and VT. Kayrak $e t a l^{17}$ described a case of VT in a patient aged 56 years that was successfully cardioverted and had an ICD subsequently implanted. Malhotra $e t a l^{18}$ described a man aged 33 years with VT in whom an ICD was also implanted. Baral et $a l^{19}$ identified a woman aged 
48 years with decompensated cardiac failure and incessant VT that was treated with ablation. Although VT was not specified, Petit et $a l^{20}$ identified a woman aged 29 years with a rhythm described as a wide complex tachycardia. Ventricular fibrillation was identified in a man aged 49 years with ccTGA in Vancouver ${ }^{21}$ and Harrison et $a l^{22}$ described the case of a man aged 31 years with syncope who had an ICD implanted. In a population of patients with TGA and Senning or Mustard repair, VT or fibrillation was the rhythm recorded in 21 of 47 cases of sudden death. ${ }^{13}$

ICD implantation is currently recommended in young adults with congenital heart disease for survivors of SCD (reversible cause excluded), those with unexplained syncope and impaired ventricular function once a reversible cause has been excluded and for those with spontaneous sustained VT if catheter ablation or surgical resection is not successful. ${ }^{23}$ Khanna et al reviewed clinical, implantation and follow-up data on all transvenous ICDs in adults with a variety of congenital heart disease, including 12 patients with ccTGA $(17 \%)$, at the Mayo Clinic from 1991 through 2008. The commonest indication for ICD implantation was sustained ventricular arrhythmias or primary prevention. They reported no major implant-related complications and found that the likelihood of an appropriate ICD discharge was associated with increased subpulmonic ventricular pressure. ${ }^{24}$

\section{Limitations}

This study was limited by its retrospective nature; however, we believe our experience highlights the importance of improving risk stratification in adults with this type of congenital heart disease. The rarity of this congenital condition means that our report includes a relatively small number of patients, thereby making it difficult to draw conclusions. There was selection bias as patients were selected from a tertiary centre, and the true denominator for the number of patients with this condition remains unknown. However, given that we are the only state-wide tertiary centre for ACHD, we do believe that we have captured a reasonably accurate picture of the outcomes for the local ccTGA population. We speculate that the outcomes of patients followed up at tertiary centres are better than those not under specialist follow-up; thus, the true incidence of SCD in this cohort is higher than our observed incidence. Supporting data obtained from the National Death Index ensures that, although we do not have the true denominator of patients, at least the vital status of all the patients that were followed up by our service was ascertained.

We recorded the results of TTEs performed on our patients. These results were generally qualitative assessments of RV function rather than an objective measure of RV function. Quantitative methods of measuring RV function by echocardiography have not been defined for systemic right ventricles; hence, a quantitative assessment was performed by experienced ACHD sonographers. Performance of routine, serial cardiac MRI was not part of clinical practice during the study period. This limited a more in-depth analysis of the relationship between the reported RV function and documented symptoms or arrhythmias. Given the rarity of this condition, a multi-institutional collaborative study into SCD in ccTGA with a unified data collection and entry system could provide more comprehensive information on risk and risk stratification.

\section{CONCLUSION}

ccTGA is a rare and complex disease, the natural and operated history of which depends heavily on the presence and severity of associated cardiac abnormalities. Owing to the increasing numbers of patients with ccTGA surviving into adulthood, more cardiologists are likely to encounter patients with deteriorating RV function and rhythm abnormalities. The occurrence of five cases of sudden death in a relatively small cohort, despite regular review of structural and electrical function of the heart, suggests that further risk stratification is needed. ICD implantation may emerge as a potentially life-saving therapy for appropriately selected patients.

Acknowledgements PC is supported by a cofunded scholarship from the National Health and Medical Research Council and the National Heart Foundation-Scholarship Number 1055773.

Contributors All authors contributed to drafting and editing the manuscript. Authors $1-5$ also contributed to data collection by reviewing records as well as by reviewing the mortality data.

Competing interests None declared.

Ethics approval Royal Prince Alfred Hospital, Sydney, HREC.

Provenance and peer review Not commissioned; externally peer reviewed.

Data sharing statement No additional data are available.

Open Access This is an Open Access article distributed in accordance with the Creative Commons Attribution Non Commercial (CC BY-NC 4.0) license, which permits others to distribute, remix, adapt, build upon this work noncommercially, and license their derivative works on different terms, provided the original work is properly cited and the use is non-commercial. See: http:// creativecommons.org/licenses/by-nc/4.0/

\section{REFERENCES}

1. Allen HD, Driscoll DJ, Feltes DF, et al. Heart Disease - In Infants Children, and Adolescents : Including the Fetus and Young Adult 8th ed. Philadelphia: Wolters Kluwer Health/Lippincott Williams \& Wilkins, 2013:1147-58.

2. Ferencz C, Rubin JD, McCarter RJ, et al. Congenital heart disease: prevalence at livebirth. The Baltimore-Washington Infant Study. Am J Epidemiol 1985;121:31-6.

3. [No authors listed]. Report of the New England Regional Infant Cardiac Program. Pediatrics 1980;65(2 Pt 2):375-461.

4. Samánek M, Vorisková M. Congenital heart disease among 815,569 children born between 1980 and 1990 and their 15-year survival: a prospective Bohemia survival study. Pediatr Cardiol 1999;20:411-17.

5. Graham TP Jr, Bernard YD, Mellen BG, et al. Long-term outcome in congenitally corrected transposition of the great arteries: a multi-institutional study. J Am Coll Cardiol 2000;36:255-61.

6. Benson LN, Burns R, Schwaiger M, et al. Radionuclide angiographic evaluation of ventricular function in isolated congenitally corrected transposition of the great arteries. Am J Cardiol 1986;58:319-24.

7. Oechslin EN, Harrison DA, Connelly MS, et al. Mode of death in adults with congenital heart disease. Am J Cardiol 2000;86:1111-16. 
8. Verheugt CL, Uiterwaal CS, van der Velde ET, et al. Mortality in adult congenital heart disease. Eur Heart $J$ 2010;31:1220-9.

9. Koyak Z, Harris L, de Groot JR, et al. Sudden cardiac death in adult congenital heart disease. Circulation 2012;126:1944-54.

10. Basso C, Frescura C, Corrado D, et al. Congenital heart disease and sudden death in the young. Hum Pathol 1995;26:1065-72.

11. Warnes CA. Transposition of the great arteries. Circulation 2006;114:2699-709.

12. Connelly MS, Liu PP, Williams WG, et al. Congenitally corrected transposition of the great arteries in the adult: functional status and complications. J Am Coll Cardiol 1996;27:1238-43.

13. Prieto LR, Hordof AJ, Secic M, et al. Progressive tricuspid valve disease in patients with congenitally corrected transposition of the great arteries. Circulation 1998;98:997-1005.

14. Piran S, Veldtman G, Siu S, et al. Heart failure and ventricular dysfunction in patients with single or systemic right ventricles. Circulation 2002;105:1189-94.

15. Kammeraad JA, van Deurzen $\mathrm{CH}$, Sreeram N, et al. Predictors of sudden cardiac death after Mustard or Senning repair for transposition of the great arteries. J Am Coll Cardiol 2004;44:1095-102.

16. van der Bom T, Winter MM, Groenink M, et al. Right ventricular end-diastolic volume combined with peak systolic blood pressure during exercise identifies patients at risk for complications in adults with a systemic right ventricle. J Am Coll Cardiol 2013;62:926-36.

17. Kayrak M, Kaya Z, Gul EE, et al. Congenitally corrected transposition of great arteries with severe rhythm disturbances. Indian Pacing Electrophysiol J 2010;10:179-83.
18. Malhotra S, Patel RN, Mandawat M. A case of congenitally corrected transposition of the great arteries with rare but life-threatening ventricular tachycardia and a coincidental single coronary ostium. J Invasive Cardiol 2007;19:E139-41.

19. Baral VR, Veldtman GR, Yue AM, et al. Successful percutaneous ablation of ventricular tachycardia in congenitally corrected transposition of the great arteries, a case report. J Interv Card Electrophysiol 2004;11:211-15.

20. Petit J, Lancelin B, Cabanis C, et al. Hisian tachycardia in an adult with corrected transposition of great vessels. Arch Mal Coeur Vaiss 2004;72:113-7.

21. Almahmeed W, Haykowski M, Boone J, et al. Congenitally corrected transposition of the great arteries and exercise-induced ventricular tachycardia. Can J Cardiol 1996;12:526-8.

22. Harrison DA, Connelly M, Harris L, et al. Sudden cardiac death in the adult with congenital heart disease. Can J Cardiol 1996;12:1161-3.

23. Baumgartner $\mathrm{H}$, Bonhoeffer $\mathrm{P}, \mathrm{De}$ Groot NM, et al. Task Force on the Management of Grown-up Congenital Heart Disease of the European Society of Cardiology (ESC); Association for European Paediatric Cardiology (AEPC); ESC Committee for Practice Guidelines (CPG). ESC Guidelines for the management of grown-up congenital heart disease (new version 2010). Eur Heart $J$ 2010;31:2915-57.

24. Khanna AD, Warnes CA, Phillips SD, et al. Single-center experience with implantable cardioverter-defibrillators in adults with complex congenital heart disease. Am J Cardiol 2011;108:729-34. 